\title{
SURGICAL RECONSTRUCTION OF THE POSTERIOR MEATAL WALL BY BIOGLASS VERSUS TITANIUM MESH
}

\author{
Samir S Sorour, Nasser N Mohammed, Magdy M Abdel Fattah and Mohammed E Abdel Bary \\ Otorhinolaryngology department Faculty of Medicine, Zagazig University, Egypt.
}

\begin{abstract}
Background: Canal wall down mastoidectomy has many drawbacks including chronic otorrhea not responding to medications, granulations, dizziness on exposure to cold or hot water, and tendency of debris accumulation in the mastoid cavity, necissating periodic cleaning. Many of these proplems can be solved by reconstruction of the posterior meatal wall. Aim of work: To solve the cavity proplems after CWD mastoidectomy via reconstruction of posterior meatal wall, and to compare between the outcomes of the Bioglass versus titanium mesh in reconstruction of posterior meatal wall. Patients and methods: This study was applied on 40 patients that have chronic sappurative otitis media. All cases were subjected to canal wall down mastoid surgery with complete elimination of the disease and reconstruction of the posterior meatal wall. Patients were divided to 2 groups: group (A) was managed by canal wall down mastoidectomy with reconstruction of the posterior meatal wall by Bioglass and the group (B) was managed by canal wall down mastoidectomy with reconstruction of the posterior meatal wall by titanium micromesh; all patients were exposed to full preoperative evaluation, and full postoperative assessment of complications, appearance of the external auditory canal contour, and the hearing gain expressed by the change of the air bone gap postoperatively. Results: There is a significant difference between the two groups regarding postoperative complications mainly the postoperative granulations and discharge, the postoperative appearance of the external auditory canal contour, and the hearing gain in favor of group (A) but there is no significant difference between the 2 groups as regard the intraoperative difficulties, the other postoperative complications like wound infection, canal stenosis, extrusion or displacement of the materials and recurrence of cholesteatoma. Conclusion: Reconstruction of posterior canal wall can eliminate many of the cavity proplems after CWD mastoidectomy especially by using the Bioglass which shows better advantages than the titanium micromesh
\end{abstract}

Keywords: canal wall reconstruction, Bioglass, titanium, mastoidectomy, mastoid cavity oblitration

\section{INTRODUCTION}

$\mathbf{T}$ he surgery of chronic otitis media with cholesteatoma is aiming at obtaining a dry, safe ear through removal of disease and prevention of recurrence. Canal wall up (CWU) mastoidectomy has many advantages including preservation of the posterior canal wall, avoiding recurrent mastoid cavity cleaning and avoiding recurrent mastoid cavity infections. However, the recurrence rate is very high about $36 \%$ in adults and $67 \%$ in children ${ }^{1}$.

In canal wall down (CWD) mastoidectomy procedure the posterior meatal wall is removed providing exposure of the entire attic, especially the region of the anterior zygomatic cell tract, exposure of the entire epitympanum and middle ear, helping to ensure complete disease eradication. So the recurrence rate is $2 \%$ in this procedure ${ }^{2}$.
Canal wall down mastoidectomy has many drawbacks like cavity proplems (chronic otorrhea, granulations, dizziness in cold or hot water, and accumulation of debris in the exteriorized mastoid cavity, requiring periodic cleaning), social handicaps (nonesthetic meatoplasty, water restrictions to prevent bowl infections) or hearing problems (major conductive or mixed hearing loss as the ossicular chain reconstruction is very difficult, difficult hearing aid application) ${ }^{3}$.

Reconstruction of the posterior canal wall and the middle ear can solve some of these proplems. Many different materials, autologous as well as synthetic, have been described in the literature for obliteration of mastoid cavities, the surgery typically aims at reducing the size of difficult-to-clean radical mastoid cavities, thus restoring the normal skeleton of the external auditory canal ${ }^{4}$. 
The materials which are used in mastoid reconstruction and obliteration can be classified into two main categories: (a) Free grafts, which are further classified to biologic and nonbiologic and (b) Local flaps. ${ }^{\mathbf{5}}$

The biologic free grafts include bone pate, allogenic/autogenic bone chips, cartilage, fat and fascia. ${ }^{6}$

These biologic free grafts such as bone and fat are resorbed with time, in which case reoperation may be needed to place a new tissue substitute.

There are several types of local flaps, including the Palva flap (Meatally-based musculoperiosteal flap) ${ }^{\mathbf{8}}$, middle temporal artery flap, Hong Kong flap", temporoparietal fascial flap $(\mathrm{TPFF})^{\mathbf{1 0}}$, pedicled superficial temporalis fascial flap ${ }^{\mathbf{1 1}}$, postauricularperiosteal-pericranial flap ${ }^{\mathbf{1 2}}$, temporalis muscle flap $^{13}$, inferiorly based fascioperiosteal flap ${ }^{\mathbf{1 4}}$, and postauricular myocutaneous flap. ${ }^{\mathbf{1 5}}$

However, These biologic free grafts and local flaps are associated with donor-site morbidity and new cavity formation after tissue retraction $^{\mathbf{1 6}}$, also free muscle graft used as an obliteration material loses its bulk and morphological appearance over time ${ }^{\mathbf{1 7}}$, having an adequate amount of obliteration material available is important in difficult mastoid cavity cases, and this might be a limitation of autogenous materials. ${ }^{18}$

Much of these proplems can be avoided with the synthetic obliteration materials (non biologic free grafts), like hydroxyapatite crystals, calcium phosphate ceramic granules, titanium and bioactive glass(BAG) ceramic to reconstruct the canal wall after CWD mastoidectomy. ${ }^{19}$

Synthetic materials should be biocompatible, shouldn't be extruded or resorbed, measurable, and should allow sound transmission. ${ }^{\mathbf{2 0}}$

Properties of BAG include induction of new bone formation ${ }^{21}$, biocompatibility and absence of toxic properties ${ }^{22}$, and antibacterial effects for a wide array of clinically important Bacteria. $^{23}$

Titanium has many applications in craniofacial, ear, and orthopedic procedures. It is biocompatible and can osteointegrate with the bone ${ }^{24}$; in addition, titanium mesh is a malleable material, so it can be easily shaped according to the surgical requirements ${ }^{25}$

\section{PATIENTS AND METHODS}

Selection of patients

From May 2012 to February 2015, 40 patients (21 male patients and 19 female patients) their ages ranged from 12 to 36 years underwent canal wall down mastoid surgery with complete elimination of the disease and reconstruction of the posterior meatal wall in Otolaryngology Head and Neck Surgery Department, Zagazig University Hospitals. All the cases included in this study were operated for the first time. They were suffering from chronic ear discharge ( 7 patients with granulation tissue and 33 with cholesteatoma ). Patients were divided to 2 groups: one group was managed by canal wall down mastoidectomy with reconstruction of the posterior meatal wall by Bioglass and the other group was managed by canal wall down mastoidectomy with reconstruction of the posterior meatal wall by titanium micromesh. They all underwent:

\section{- Pre-operative evaluation}

All patients in the study had done basic preoperative assessment, which include the following:

- Thorough general examination and ENT examination

\section{- Audiological assessment}

- Tympanometry.

- $\quad$ Pure tone audiometry (PTA)

- Imaging

- $\quad$ Computerized tomography (CT scan) of the temporal bone. There is no need for the MRI preoperatively as the matter is to reconstruct the posterior meatal wall after CWD mastoidectomy not the differentiation between cholesteatoma and the granulations.

- An informed consent had been taken from all the patients in this study

\section{Surgical techniques}

1- Group (A): 
Twenty cases were managed by CWD with reconstruction of the posterior canal wall by Bioglass

\section{1-Incision}

Postauricular incision starts just above the pinna down to the mastoid tip
2- Creation of postauricular superiorly based muscloperiosteal flap

This is done by cutting the postauricular subcutaneous soft tissue including the underlying periosteum down to mastoid cortex figure (1).

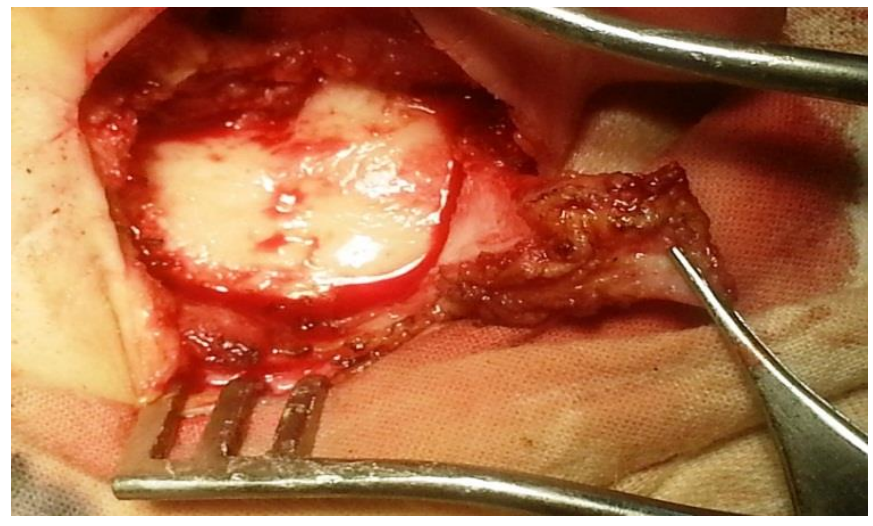

Figure (1) postauricular muscloperiosteal flap

\section{3- Preparation of temporalis fascia graft}

It should be large enough to be used for covering the newly reconstructed posterior canal wall and grafting the tympanic membrane perforation.

\section{4- Management of the middle ear}

It is started by elevating the tympanomeatal flap carefully, trying to keep it intact, then entering the middle ear to remove any pathological lesions.

\section{5- Management of the mastoid}

Classic CWD mastoidectomy with removal of the posterior \& superior bony canal wall to the level of the facial nerve, and if needed the incus and the head of the malleus are removed to gain access to the epitympanic recess if there is any doupt of presence of remanant pathology there.

6- Reconstruction of the posterior meatal wall

It is done via the following steps:-

\section{A-Preparation of the templates}

Two foil templates give the accurate measurements and the degree of curvature of the posterior meatal wall have been used. B-preparation of the Bioglass mixture
It is done by mixing the Bioglass in its particulate form with either venous blood or saline but we prefer to mix it with venous blood as it hardens faster. figure (2).

C-Positioning of the Bioglass mixture between the two foil templates

The Bioglass mixture is inserted between the foil templates from the depth to the surface till the whole wall is reconstructed figure (3).

\section{D-Removal of the foil templates}

After the building of the newly reconstructed posterior meatal wall by the Bioglass mixture had been finished the two foil templates and the supporting pieces of cotton placed in external auditory canal and the mastoid cavity all are removed so the newly reconstructed posterior meatal wall became apparent figure (4).

E-Reconstruction of the tympanic membrane

The prepared temporalis fascia graft is used to reconstruct the tympanic membrane perforation which should be large enough to be extended over the newly reconstructed posterior meatal wall.

F-Rotation of the post auricular muscloperiosteal flap in the mastoid cavity 
After reconstruction of the posterior meatal wall is completed the prepared post auricular superiorly based muscloperiosteal flap is rotated into the mastoid cavity aiming at not only obliteration of the mastoid cavity to reduce its size but also supporting the newly reconstructed posterior meatal wall figure (5).

G-Repositioning of the tympanomeatal flap against the newly reconstructed posterior meatal wall

This is assured carefully and maintained by packing the external auditory canal by

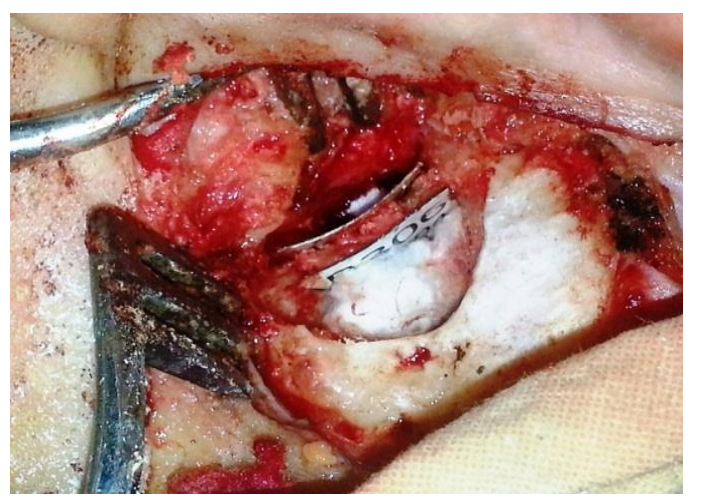

Figure (2) Bioglass mixture

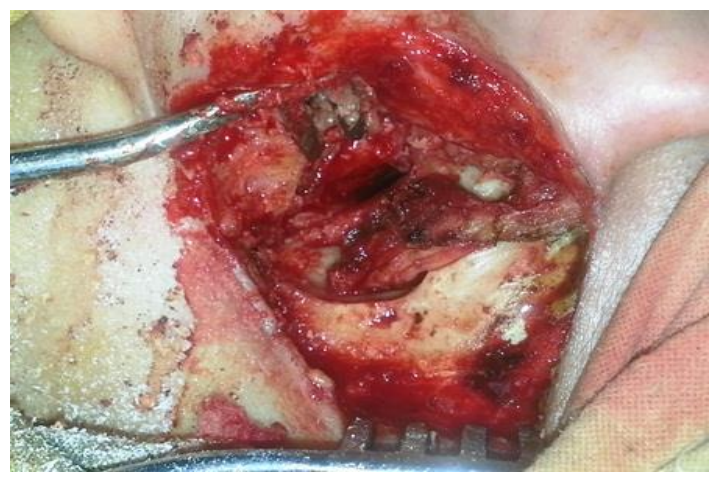

Figure (4) The newly reconstructed posterior meatal wall after removal of the foil templates

\section{2-Group (B):}

\section{1-Group (B):}

Twenty cases were managed by CWD mastoidectomy with reconstruction of the posterior canal wall by titanium micromesh. The titanium mesh used in this study is $0.1 \mathrm{~mm}$ thick, with $2 \mathrm{~mm}$ pores (Titanium Micromesh, JEIL medical corporation, Seoul, Korea) figure (6) sufficient amount of gelfoam. So the newly reconstructed posterior meatal wall consists of Bioglass layer, temporalis fascia graft and the tympanomeatal flap. The temporalis fascia graft is applied over the newly reconstructed wall before repositioning of the tympanomeatal flap to avoid any possibility of exposure of any part of the new wall as the flap is not always kept intact during the elevation.

\section{7- Closure of the wound}

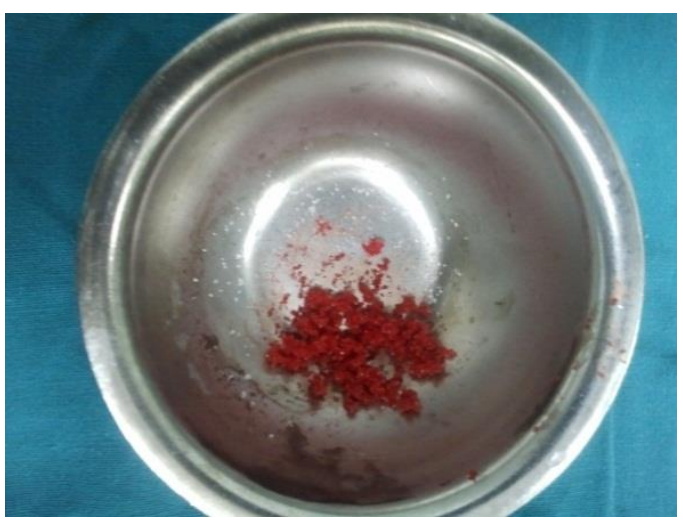

Figure (3) Bioglass mixture between the two foil templates

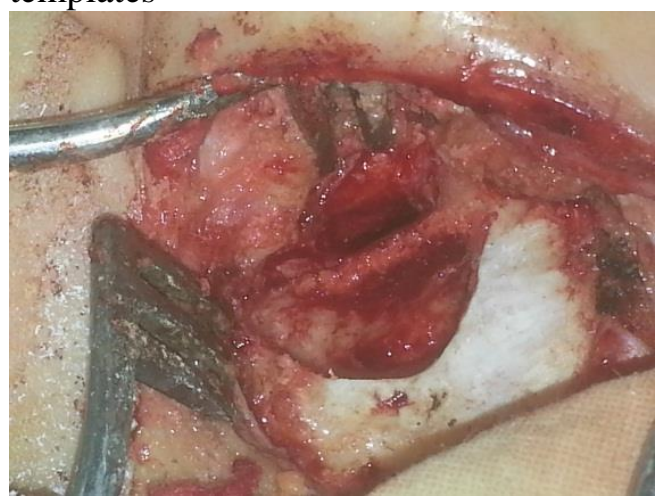

Figure (5) Rotation of the postauricular muscloperiosteal flap inside the mastoid cavity

\section{1-Incision}

2- Creation of postauricular superiorly based muscloperiosteal flap

3- Preparation of temporalis fascia graft

4- Management of the middle ear pathology

5- Management of the mastoid

As in Surgical technique for group (A), but early in this step a sufficient amount of bone pate is collected from healthy bone of the 
mastoid, squamaous temporal bone, and the zygomatic root. The collected bone pate is mixed with antibiotic like Chloramephinicol or Bacitracin figure (7).

6- Reconstruction of the posterior meatal wall

It is done via the following steps:-

A-Creation of grooves :

2- to 3-mm cutting burr is used to drill two deep grooves into the bone along the facial ridge posteriorly and inferiorly and along the anterior-superior wall of the meatus figure (8).

\section{B-Preparation of the template}

A foil template gives the accurate measurements and the curvature of the posterior canal wall has been used to get the template.

\section{C-Preparation of the titanium micromesh}

Using the foil template as a model, the prosthetic wall is cut from the titanium micromesh figure (9).

D-Insertion of the titanium micromesh in the created grooves

The mesh is then folded and placed into the created grooves. A little tail is doe in the mesh to allow the fixation of the mesh with one or two titanium screws to the cavity borders figure(10).

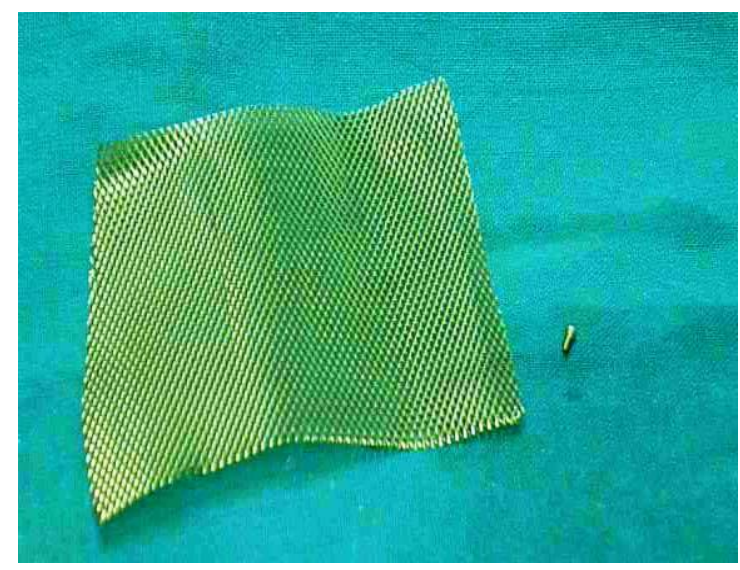

Figure (6) titanium micromesh and titanium screw
E- Covering titanium micromesh with bone pate

The collected bone pate' is used to cover the meatal surface of the mesh completely. The titanium mesh support the covering bone pate' that will become viable bone later on figure (11).

\section{F- Reconstruction of the tympanic} membrane

The prepared temporalis fascia graft is used to reconstruct the tympanic membrane perforation which should be large enough to be extended over the newly reconstructed posterior meatal wall.

\section{G- Rotation of the post auricular} muscloperiosteal flap in the mastoid cavity H- Repositioning of the tympanomeatal flap against the newly reconstructed posterior meatal wall

This is assured carefully and maintained by packing the external auditory canal by sufficient amount of gelfoam .So the newly reconstructed posterior meatal wall consists of titanium micromesh, bone pate sheet,temporalis fascia graft and the tympanomeatal flap 7- Closure of the wound

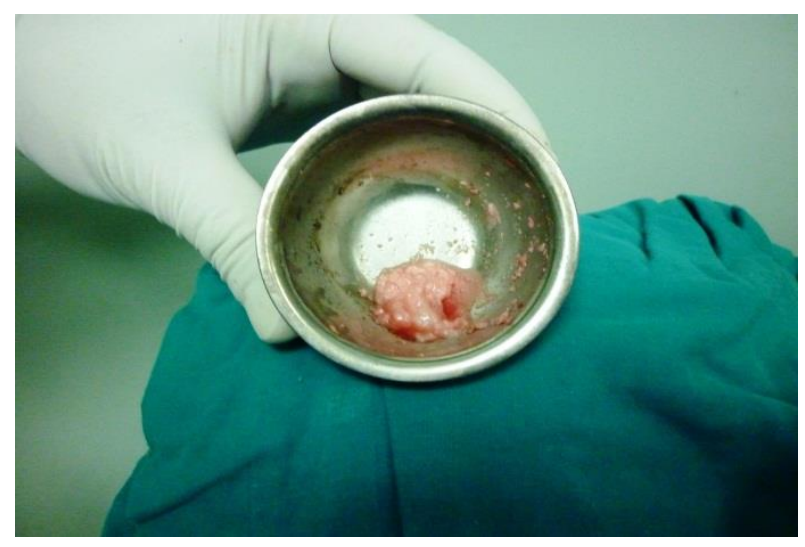

Figure (7) The collected bone pate 


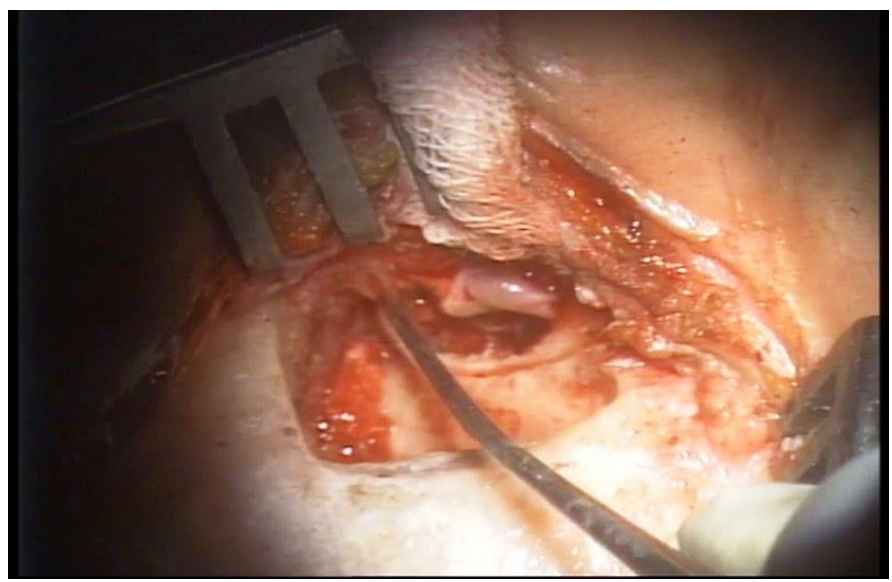

figure (8) Creation of two grooves

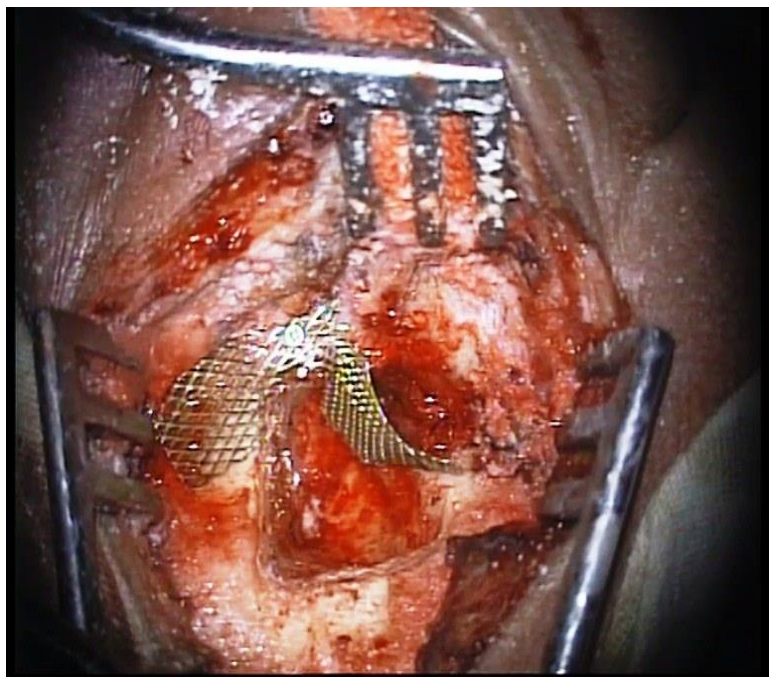

Figure (10) titanium mesh fixed to cavity border by titanium screw

\section{Follow up:}

This include :-

- Systemic antibiotics for 2 weeks

-Removal of the dressing and the stitches after 1 week, then application of topical ear drops for 2 weeks.

-Otoscopic and otoendoscopic examinations are done weekly for the first month, then monthly in the first 3 monthes, then every 3 monthes afterwards .

-Pure tone audiometry and CT temporal bone are done 1 year postoperative .

\section{STATISTICAL ANALYSIS}

All data were analyzed using SPSS 22.0 for windows (SPSS Inc., Chicago, IL, USA) \& MedCalc 13 for windows (MedCalc Software
Figure (9) titanium mesh and the foil template

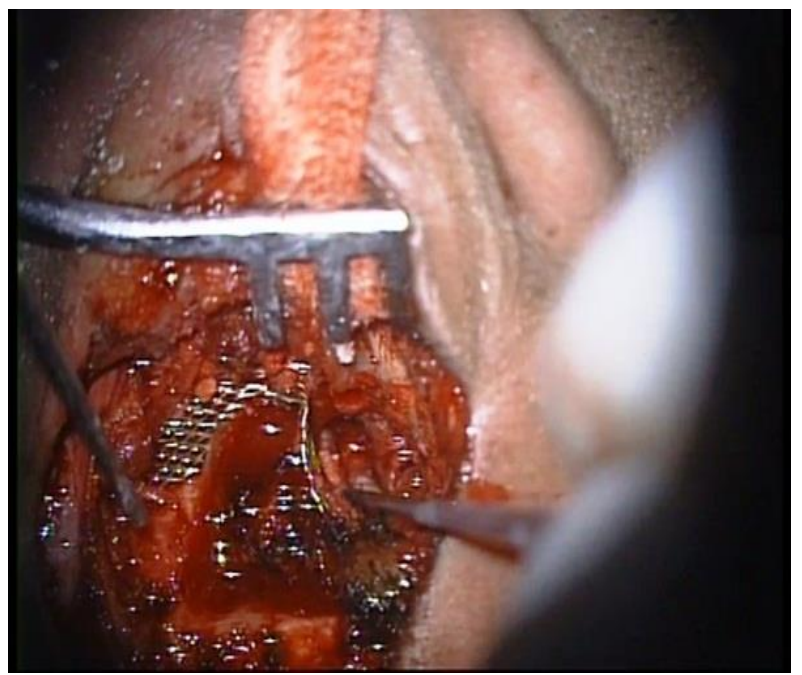

Figure (11) Covering of the titanium mesh by a sheet of bone pate

bvba). Continuous variables were expressed as the mean \pm SD \& median (range), and the categorical variables were presented as a number (percentage). Continuous variables were checked for normality by using ShapiroWilk test. Mann-Whitney U (MW) test was used to compare between two groups of nonnormally distributed data. Wilcoxon Signed Ranks (WSR) test was used to compare non normally distributed data between two dependent groups. Percent of categorical variables were compared using the Chi-square $(\chi 2)$ test. $\mathrm{p}<0.05$ was considered statistically significant $(\mathrm{S}), \mathrm{p}<0.01$ was considered highly statistically significant (HS), and $p \geq 0.05$ was considered non statistically significant (NS). 
Table (1): Approaches used in the study.

\section{RESULTS}

\begin{tabular}{|c|c|c|}
\hline & Group A & Group B \\
\hline Approach & $\begin{array}{l}\text { Reconstruction of the } \\
\text { posterior meatal wall by } \\
\text { Bioglass }\end{array}$ & $\begin{array}{l}\text { Reconstruction of the } \\
\text { posterior meatal wall by } \\
\text { titanium micromesh }\end{array}$ \\
\hline Number of patients & 20 & 20 \\
\hline
\end{tabular}

Table (2): Preoperative air bone gab (ABG).

\begin{tabular}{|c|c|c|c|c|}
\hline $\begin{array}{l}\text { Air bone gab } \\
\text { (ABG) }\end{array}$ & $\begin{array}{l}\text { Group A } \\
(\mathrm{N}=20)\end{array}$ & $\begin{array}{l}\text { Group B } \\
(\mathrm{N}=20)\end{array}$ & MW & $\begin{array}{l}\text { p-value } \\
\text { (Sig) }\end{array}$ \\
\hline Mean \pm SD & $29.5 \pm 9.2$ & $28.1 \pm 6.3$ & \multirow{3}{*}{-0.108} & \multirow{3}{*}{0.914} \\
\hline Median & 26 & 27.5 & & \\
\hline Range & $19-50$ & $20-42$ & & \\
\hline
\end{tabular}

MW: Mann Whitney U test.

$\mathrm{p}<0.05$ is significant.

Sig: significance.

Table (3): Intraoperative pathology.

\begin{tabular}{|c|c|c|c|c|c|c|}
\hline \multirow[b]{2}{*}{$\begin{array}{l}\text { Intraoperative } \\
\text { pathology }\end{array}$} & \multicolumn{2}{|c|}{$\begin{array}{l}\text { Group A } \\
(\mathrm{N}=20)\end{array}$} & \multicolumn{2}{|c|}{$\begin{array}{l}\text { Group B } \\
(\mathrm{N}=20)\end{array}$} & \multirow{2}{*}{$\chi^{2}$} & \multirow{2}{*}{$\begin{array}{l}\text { p-value } \\
\text { (Sig) }\end{array}$} \\
\hline & No. & $\%$ & No. & $\%$ & & \\
\hline Cholesteatoma & 16 & $80 \%$ & 17 & $85 \%$ & \multirow{2}{*}{0.000} & \multirow{2}{*}{$\begin{array}{l}1.000 \\
(\mathrm{NS})\end{array}$} \\
\hline Granulations & 4 & $20 \%$ & 3 & $15 \%$ & & \\
\hline
\end{tabular}

$\chi^{2}$ : Chi-square test.

$\mathrm{p}<0.05$ is significant.

As shown in table (3) there were 33 cases with cholesteatoma, while 7 cases with granulations among the total 40 cases included in the study. 
Table (4): Postoperative complications.

\begin{tabular}{|c|c|c|c|c|c|c|}
\hline \multirow{2}{*}{$\begin{array}{l}\text { Postoperative } \\
\text { complications }\end{array}$} & \multicolumn{2}{|c|}{$\begin{array}{l}\text { Group A } \\
(\mathrm{N}=20)\end{array}$} & \multicolumn{2}{|c|}{$\begin{array}{l}\text { Group B } \\
(\mathrm{N}=20) \\
\end{array}$} & \multirow{2}{*}{$\chi^{2}$} & \multirow{2}{*}{$\begin{array}{l}\text { p-value } \\
\text { (Sig) }\end{array}$} \\
\hline & No. & $\%$ & No. & $\%$ & & \\
\hline Wound infection & 2 & $10 \%$ & 8 & $40 \%$ & 3.333 & $\begin{array}{c}0.067 \\
(\mathrm{NS})\end{array}$ \\
\hline $\begin{array}{l}\text { Facial nerve } \\
\text { Paralysis }\end{array}$ & 2 & $10 \%$ & 1 & $5 \%$ & 0.000 & $\begin{array}{l}1.000 \\
(\mathrm{NS})\end{array}$ \\
\hline $\begin{array}{l}\text { Canal } \\
\text { stenosis }\end{array}$ & 2 & $10 \%$ & 4 & $20 \%$ & 0.196 & $\begin{array}{l}0.657 \\
(\mathrm{NS})\end{array}$ \\
\hline $\begin{array}{l}\text { Recurrence of } \\
\text { Cholesteatoma }\end{array}$ & 1 & $5 \%$ & 4 & $20 \%$ & 0.914 & $\begin{array}{c}0.339 \\
(\mathrm{NS})\end{array}$ \\
\hline $\begin{array}{l}\text { Extrusion and or } \\
\text { displacement of } \\
\text { the material }\end{array}$ & 2 & $10 \%$ & 6 & $30 \%$ & 1.406 & $\begin{array}{l}0.235 \\
(\mathrm{NS})\end{array}$ \\
\hline Granulations & 0 & $0 \%$ & 10 & $50 \%$ & 10.800 & $\begin{array}{l}0.001 \\
(\mathrm{HS}) \\
\end{array}$ \\
\hline Discharge & 2 & $10 \%$ & 10 & $50 \%$ & 5.833 & $\begin{array}{c}0.015 \\
(\mathrm{~S})\end{array}$ \\
\hline $\begin{array}{l}\text { Residual TM } \\
\text { Perforation }\end{array}$ & 3 & $15 \%$ & 10 & $50 \%$ & 4.103 & $\begin{array}{l}0.042 \\
(\mathrm{NS})\end{array}$ \\
\hline $\begin{array}{l}\text { Total cases with } \\
\text { one or more } \\
\text { complications }\end{array}$ & 5 & $25 \%$ & 10 & $50 \%$ & 1.707 & $\begin{array}{l}0.191 \\
(\mathrm{NS})\end{array}$ \\
\hline
\end{tabular}

As shown in Table (4), there is significant difference in favor to group (A) regarding postoperative complications namely postoperative granulations, and discharge. Facial nerve paralysis had occurred in 3 cases, it was discovered immediately postoperative in the form of partial LMNL facial paralysis, in these 3 cases the facial nerve was exposed intraoperative by the effect of the eroding cholesteatoma and or granulations. It was managed by conservative treatment in the form of removal of the aural pack, steroids, and physiotherapy. All cases were improved during the follow up.

Table (5): Postoperative appearance of external auditory canal (EAC) contour.

\begin{tabular}{|c|c|c|c|c|c|c|}
\hline \multirow[b]{2}{*}{ EAC appearance } & \multicolumn{2}{|c|}{$\begin{array}{c}\text { Group A } \\
(\mathrm{N}=20)\end{array}$} & \multicolumn{2}{|c|}{$\begin{array}{l}\text { Group B } \\
(\mathrm{N}=20)\end{array}$} & \multirow{2}{*}{$\chi^{2}$} & \multirow{2}{*}{$\begin{array}{c}\text { p-value } \\
\text { (Sig) }\end{array}$} \\
\hline & No. & $\%$ & No. & $\%$ & & \\
\hline Smooth contour & 17 & $85 \%$ & 6 & $30 \%$ & \multirow{2}{*}{10.230} & \multirow{2}{*}{$\begin{array}{c}0.001 \\
(\mathrm{HS})\end{array}$} \\
\hline Irregular contour & 3 & $15 \%$ & 14 & $70 \%$ & & \\
\hline
\end{tabular}

$\chi 2$ : Chi-square test.

$\mathrm{p}<0.05$ is significant.

Sig: significance. 
As shown in Table (5) there is significant difference between the two groups regarding Postoperative appearance of external auditory canal (EAC) contour in favor to group (A)

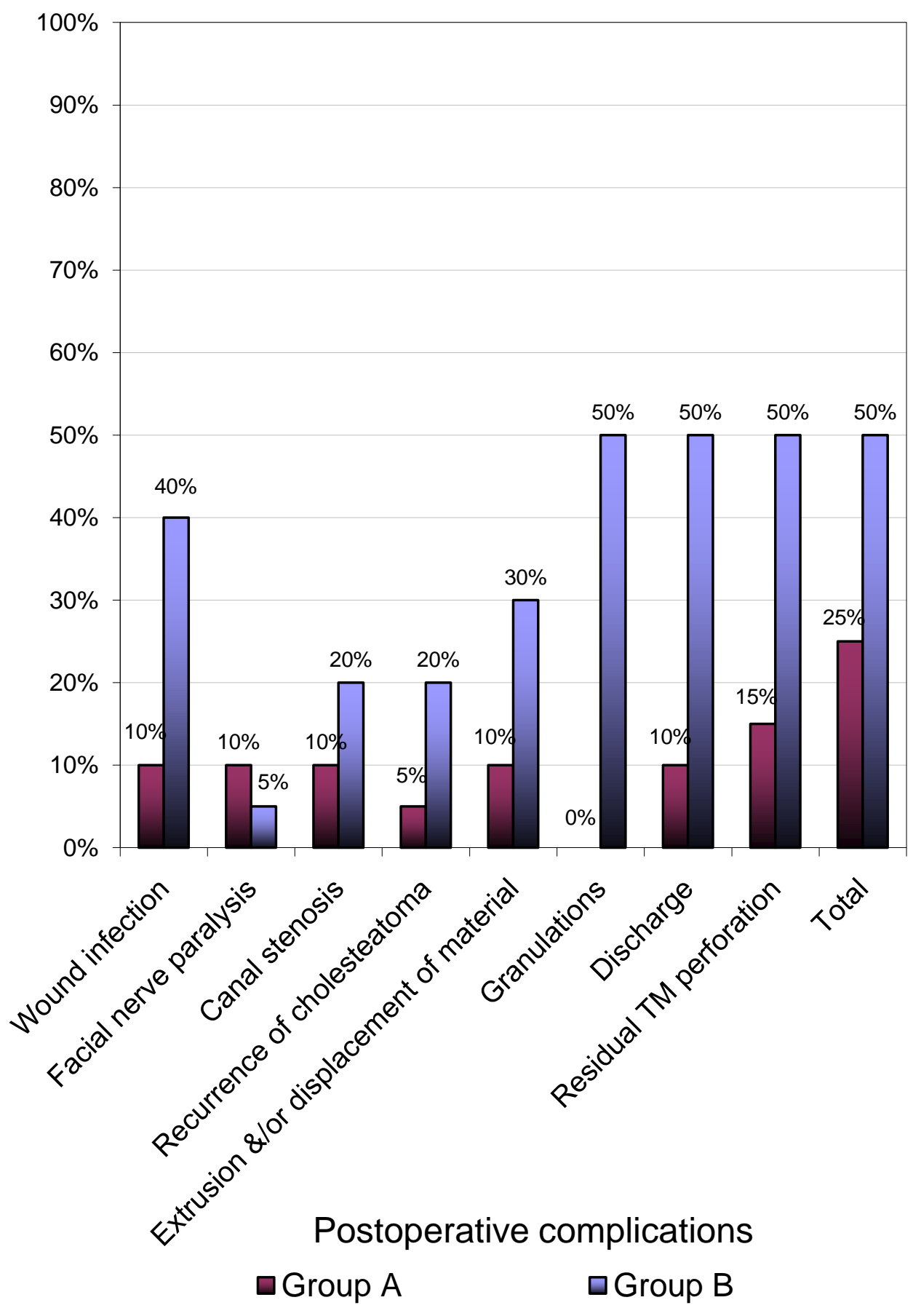

Fig. (12): Bar chart shows postoperative complications. 
Table (6): Postoperative air bone gab (ABG).

\begin{tabular}{|c|c|c|c|c|}
\hline $\begin{array}{l}\text { Air bone gab } \\
\text { (ABG) }\end{array}$ & $\begin{array}{l}\text { Group A } \\
(\mathrm{N}=20)\end{array}$ & $\begin{array}{l}\text { Group B } \\
(\mathrm{N}=20)\end{array}$ & MW & $\begin{array}{c}\text { p-value } \\
\text { (Sig) }\end{array}$ \\
\hline Mean \pm SD & $18.7 \pm 9.2$ & $29.6 \pm 6.1$ & \multirow{3}{*}{-4.102} & \multirow{3}{*}{$\begin{array}{c}<0.001 \\
(\mathrm{HS})\end{array}$} \\
\hline Median & 18.5 & 27.5 & & \\
\hline Range & $5-40$ & $22-42$ & & \\
\hline
\end{tabular}

MW: Mann Whitney U test.

$\mathrm{p}<0.05$ is significant.

Sig: significance.

As shown in Table (6), there is significant difference in favor to group (A) regarding postoperative hearing gain expressed in the form of Postoperative air bone gab (ABG).

\section{DISCUSSION}

In canal wall up (CWU) mastoidectomy the posterior canal wall is preserved, so it avoids the need for recurrent bowl cleaning and recurrent bowl infection. But the recurrence rate is very high $(36 \%$ in adults and $67 \%$ in children). ${ }^{1}$ However, canal wall-down mastoidectomy is an easy procedure, takes less operative time, needs less surgical experience than the CWU procedures, and has low recurrence and residual rate so it is the most commonly used surgical procedure for management of cholesteatoma worldwide. ${ }^{26}$ Surgical techniques used for management of open mastoid cavity include obliteration (cavity fill-in), reconstruction (canal wall defect repair) and ablation (external canal closure). The obliteration technique involves filling the open mastoid cavity with pedicled flaps and various materials such as fat, bone chips, hydroxyapatites, etc. The ablation or canal closure technique is only recommended for certaine cases, like a deaf ear with severe otorrhea. ${ }^{27}$ We have used a combination of both canal wall reconstruction in addition to mastoid cavity obliteration because it can reconstruct the ear, so the operated ear becomes physiologically, functionally and structurally near to the normal ear, in contrast to other methods.

The biomaterial is used to replace diseased or damaged tissue. Biologically inert materials do not react with host tissue, and become surrounded by non-adherent fibrous layers, so the scar formation is minimal. While, biologically active (bioactive) materials can react with host tissue, resulting in specific biological responses at the interface, leading to the formation of biological bonds. ${ }^{28}$

Bioglass ${ }^{\circledR}$ "45S5" is a bioactive glass ceramics which consists of of $45 \%$ silicone dioxide, $24.5 \%$ calcium oxide, $24.5 \%$ sodium dioxide and $6 \%$ phosphorous pentoxide. ${ }^{29}$ The bioactive glass acts by series of reaction stages over the first $48 \mathrm{~h}$ of insertion. First, within minutes, sodium ions are released, so the local $\mathrm{pH}$ increases above 7.4. Such alkaline $\mathrm{PH}$ induces an antimicrobial effect within the local tissues. ${ }^{30}$ Within $12 \mathrm{~h}$, the glass surface further reacts with the local aqueous environment to create an amorphous calcium phosphate layer. Then, over a further $12 \mathrm{~h}$, the calcium phosphate layer crystallizes into a hydroxycarbonate apatite layer, which resembles bone matrix in structure. It is this final layer, which entraps the ingrowing collagen fibers to create an adherent fibrous capsule and thus a biological bond. So, within $48 \mathrm{~h}$, the implant is coated with a surface of synthetic bone-like material that promotes both hard and soft tissue bonding. ${ }^{28}$

The use of titanium mesh is safe as it has been accepted by the middle ear mucosa when placed both as an ossicular prosthesis and as a free implant. There is no risk of disease transmission with the titanium as it is a 
synthetic material ${ }^{31}$. The pores present in the titanium mesh allow ingrowth of the vascular and soft tissue from the surrounding tissue through it. Also, it was found that the titanium prevents infection. ${ }^{32}$

Having an adequate amount of obliteration material available is important in difficult mastoid cavity cases, and this might be a limitation of autogenous materials. ${ }^{\mathbf{1 8}}$ With a synthetic material, on the other hand, the availability is, in principle, sufficient at all times. Harvesting an autologous graft increases the operation time and increases the risk of morbidity, and this process can be avoided with a synthetic obliteration material. ${ }^{\mathbf{3 3}}$

The conchal cartilage lacks the stability, takes long time to be reshaped, and the facial nerve may be exposed to surgical trauma during buttresses grooving ${ }^{34}$; also Dornhoffer and Simmons, 2003 reported inadequate cartilage, excessive curvature, and the difficulty of proper cutting the cartilage making it difficult to be properly fitted. However both Bioglass and titanium mesh in our study avoid these proplems as regard to the stability the Bioglass is very stable when applied and this agree with Juha Tapio Silvola (2012) who stated that BG S53P4 does not shrink after insertion. This is important for obtaining the anatomically proper volume in the obliterated area. Although BG $\mathrm{S} 53 \mathrm{P} 4$ is a resorbable material, it does not lost before the new bone has formed. Also titanium mesh is stable when applied as stated by Zini et al (2002).

Silicone, proplast, ionomer cement, ceravital and hydroxyl apatite are examples of synthetic materials have been used in canal wall reconstruction. But the silicone leads to foreign body reaction ${ }^{35}$ the use of the proplast leads to dehiscence problems 36; Infection and encephalopathy with ionomer cement ${ }^{37}$ and absorption and lysis with ceravital ${ }^{\mathbf{3 8} ; \mathbf{2 0}}$.

In this study Bioglass in its particulate form is proved to be easily prepaired and easily applied. Postoperative infection had occurred only in 2 cases $(10 \%)$ and responded well to antibiotics and conservative treatment and this confirms the antimicrobial action of the
Bioglass, and this agree with Stoor el al (2010) 39

Sarin et al (2012) ${ }^{33}$, concluded that, 23 patients $(88 \%)$ in their series had a dry, safe ear or only intermittent otorrhea, while in our study 18 patients $(90 \%)$ have a safe dry ear after reconstruction with Bioglass.

2 cases $(10 \%)$ in the Bioglass group had shown extrusion of the Bioglass particles this had occurred with the first 2 cases only where Bioglass mixture was prepared by mixing the Bioglass particles with saline unlike the other cases that were done afterwards in which the Bioglass was mixed with venous blood, this also had occurred with Sarin et al (2012) ${ }^{33}$, where protrusion of a small amount of BAG granules in 2 patients, apparently from inadequate fascia coverage of the $\mathrm{BAG}$ material, however no extrusion of the BAG granules was seen by Stoor el al (2010) ${ }^{39}$.

In this study 17 patients of the Bioglass group (85\%) shows smooth and apparently normal contour, while in Sarin et al (2012) ${ }^{\mathbf{3 3}}$ only in 7 patients(27\%), the posterior meatal wall was nearly normal in appearance.

Stoor el al (2010) ${ }^{39}$ stated that, in 6 patients (85\%) the hearing is improved, even though reconstruction of the auditory ossicles was performed in only 4 patients, while in Sarin et al (2012) ${ }^{33}$ hearing improved in 6 patients (27\%), however in our study the hearing is improved in the all 20 patients $(100 \%)$ where the mean pure tone average air-bone gap had decreased to $18.7 \mathrm{~dB}$ from $29.5 \mathrm{~dB}$, even though ossiculoplasty was performed only in 2 patients $(10 \%)$,this finding suggests that the removal of the cholesteatoma and or the granulations and the decrease in the size of the cavity and the infections causing mucosal swelling in the middle ear had an improving effect on the hearing. The lack of postoperative altered cochlear thresholds supports the fact that there is no toxic effect on the cochlea.

Zini et al (2002) ${ }^{25}$, H SUDHOFF, D BRORS, A AL-LAWATI et al (2005) ${ }^{40}$, and Jung TTK, Park SK (2004) ${ }^{41}$ had reported in their studies no postoperative infection had occurred with the use of titanium mesh, unlike 
to our results with the use of the titanium mesh where 8 patients (40\%) of group (B) had postoperative wound infection, but all of them had responded well to conservative treatment, this complication had been avoided later on with the remaining patients by giving intraoperative parenteral antibiotics including cefatriaxon $1 \mathrm{gm}$ and parenteral metronidazole (Flagyl) and maintaining this regimen 1week postoperative, also we had avoided performing this procedure in cases with active aural infections.

Zini et al (2002) ${ }^{25}$ had reported in his study that 2 patients $(22 \%)$ had developed temporary postoperative ear discharge, while in $\mathbf{H}$ SUDHOFF, D BRORS, A AL-LAWATI et al (2005) ${ }^{40}$ study a dry cavity was achieved in 13 of 15 patients $(86 \%)$, in our study 10 cases $(50 \%)$ in group (B) had developed postoperative otorrhea, only 4 cases of them had responded to conservative treatment and their ears became dry later on, while the remaining cases had not responded till the mesh had been removed later on under general anaethesia 1year postoperatively. This otorrhea is due to the partial exposure of a part of the titanium mesh postoperatively which apparently due to the lack of fixation of the mesh to the cavity borders by screws in the first 10 cases which had been done in the latter 10 cases.

All of the following studies Zini et al (2002) ${ }^{25}$, H SUDHOFF, D BRORS, A AL-LAWATI et al (2005) ${ }^{40}$, and Jung TTK, Park SK (2004) ${ }^{41}$ had reported no extrusion of the titanium mesh had occurred, unlike to our study where 6 case $(30 \%)$ had shown postoperative displacement and extrusion ended by removal of the mesh under general anaethesia 1year postoperatively this may be apparently due to the lack of fixation of the mesh to the cavity borders by screws in the first 10 cases operated in this study.

Each of Zini et al (2002) ${ }^{25}$, H SUDHOFF, D BRORS, A AL-LAWATI et al (2006) ${ }^{40}$, and Jung TTK, Park SK (2004) ${ }^{41}$ had obtained smooth contour of the canal wall with the use of the titanium mesh, while in our study only 6 cases $(30 \%)$ had shown smooth contour of the external auditory canal, which may be explained by the development of many postoperative complications including infection, otorrhea, displacement, granulations, and canal stenosis.

As regard to the postoperative hearing changes with the use of the titanium mesh neither Zini et al (2002) ${ }^{25}$ nor H SUDHOFF, D BRORS, A AL-LAWATI et al (2006) ${ }^{40}$ had shown statistically significant changes in hearing, this also agree with our results where the mean pure tone average air-bone gap had increased to $29.6 \mathrm{~dB}$ from $28.1 \mathrm{~dB}$.

So, Bioglass appears to be superior to titanium micromesh in surgical reconstruction of the posterior meatal wall, as it has low incidence of complications namely postoperative infection, otorrhea, granulations, and extrusion .

The posterior meatal wall after reconstruction by Bioglass had a smooth contour and nearly normal in appearance in 17 cases $(85 \%)$ while, the posterior meatal wall reconstructed by titanium micromesh had a smooth contour only in 3 cases (15\%).

As regard the postoperative hearing gain, the Cases operated with Bioglass had shown significant change of the postoperative air bone gab where the mean pure tone average air-bone gap had decreased to $18.7 \mathrm{~dB}$ from $29.5 \mathrm{~dB}$ while in group (B) there was no postoperative hearing gain where the mean pure tone average air-bone gap had increased to $29.6 \mathrm{~dB}$ from $28.1 \mathrm{~dB}$.

\section{CONCLUSIONS}

Surgical reconstruction of the posterior meatal wall by Bioglass appears to have less complications, smooth appearance of the posterior meatal wall and improvement of hearing. The Bioglass mixture is better prepared by venous blood than with saline.

It is advised to avoid reconstruction of the posterior meatal wall by titanium mesh in the presence of active infection in the ear, also it is better to fix the titanium mesh to the cavity borders by screw to maintain the stability of the mesh. 


\section{REFERENCES}

1. Shohet JA, de Jong AL (2002): The management of pediatric cholesteatoma. Otolaryngol Clin North Am; 35: 841-851.

2. Palva T (1987): Surgical treatment of chronic middle ear disease Canal wall up and canal wall down procedures. Acta Otolaryngol; 104: 487494 .

3. Dornhoffer JL(1999): Surgical modification of the difficult mastoid cavity. Otolaryngol Head Neck Surg; 120: 361-367.

4. Patricia Stoor, Jaakko Pulkkinen, , Reidar Grénman,(2010): Bioactive Glass S53P4 in the Filling of Cavities in the Mastoid Cell Area in Surgery for Chronic Otitis Media.Annals of Otology,Rhinology,laryngology ;119(6):377382.

5. Ching Yee Chan, Yew Meng Chan (2012): Mastoid Obliteration and Reconstruction: A Review of Techniques and Results.Proceedings of Singapore Healthcare ; 21(1):23-29.

6. Lasisi OA, Lawal HA(2007): Deep temporalis fascia in tympanomastoid reconstruction. Afr $\mathbf{J}$ Med Med Sci;36(2):183-7.

7. Zohar Y. Talmi YP. Sirauss M. Finkelstein Y. Shvilli Y(1990): Ozena revisited. J Otolaryngol:19:345-9.

8. Palva T(1993): Cholesteatoma surgery today. Clin Otolaryngol Allied Sci;18(4):245-52.

9. Hung $\mathrm{T}$, Leung $\mathrm{N}$, van Hasselt A, Kwok CL, Tong M(2007): Longterm Outcome of the Hong Kong vascularized, pedicled temporalis fascia flap in reconstruction of mastoid cavity. Laryngoscope;117(8):1403-7.

10. Cheney ML, Megerian CA, Brown MT, McKenna MJ, Nadol JB(1996): The use of the temporoparietal fascial flap in temporal bone reconstruction. Am J Otol;17(1):137-42.

11. Olson KL, Manolidis S (2002): The pedicled superficial temporalis fascia flap: a new method for reconstruction in otologic surgery. Otolaryngol Head Neck Surg;126(5):538-47.

12. Ramsey MJ, Merchant SN, McKenna MJ (2004): Postauricular Periosteal-Pericranial Flap for Mastoid Obliteration and canal wall down tympanomastoidectomy. Otol Neurotol;25(6):873-8.

13. Goel A(1994): Extended vascularized temporalis muscle-fascia flap. $\mathrm{Br}$ J Neurosurg;8(6)731-3.
14. Kahramanyol M, Ozunlu A, Pabuscu Y(2000): Fascioperiosteal flap and neo-osteogenesis in radical mastoidectomy: long-term results. Ear Nose Throat J;79(7):524-6.

15. Farrior JB(1998): Postauricular myocutaneous flap in otologic surgery. Otolaryngol Head Neck Surg;118(6):743-6.

16. Peitoia M(2004): Use of Bioactive Glass S53P4 In frontal sinus obliteration and in reconstruction of facial bone defects. Vivox-id report: Summary of clinical trials. 30(4): 16-20.

17. Linthicum $\operatorname{FH~} \operatorname{Jr}(2002)$ : The fate of mastoid obliteration tissue: a histopathological study. Laryngoscope; 112:1777-81.

18. Leatherman BD, Domhoffer JL(2004): The use of demineralized bone matrix for mastoid cavity obliteration. Otol Neurotol ;25:22-6.

19. Della Santina CC, Lee SC(2006): Ceravital reconstruction of canal wall down mastoidectomy: long-term results. Arch Otolaryngol Head Neck Surg; 132:617-23

20. El-Seifi A and Fouad B (1998): Long-term fate of plastipore in the middle ear. ORL; 60: 198201.

21. Jang CH, Cho YB, Bae CS(2007): Evaluation of bioactive glass for mastoid obliteration: a guinea pig model. In Vivo;21 : 651-5.

22. Wilson J, Pigott GH, Schoen FJ, Hench LL(1981): Toxicology and biocompatibility of bioglasses. J Biomed Mater Res; 15:805-17.

23. Leppäranta O, Vaahtio M, Peltola T, et al(2008): Antibacterial effect of bioactive glasses on clinically important anaerobic bacteria in vitro. J Mater Sei Mater Med; 19:547-51.

24. van der Pouw CTM, Johansson CB, Mylanus EAM, Albrektsson T, Crctners CWR(1998): Removal of titanium implants from the temporal bone. Histologic findings. Am J Otol: 19: 4651.

25. Zini C. Quaranta N. Piazza F(2002): Posterior canal wall reconstruction with titanium micromesh and bone pate. Laryngoscope; 114; 753-6.

26. Hulka GF, McElveen JT (1998) : Arandomized, blinded study of canal wall up versus canal wall down mastoidectomy determining the differences in viewing middle ear anatomy and pathology. Am. J. Otol. 19 (September 5) 574578.

27. Sasaki Y, Iino Y, Suzuki J-I (2002): Posterior canal wall reconstruction tympanoplasty for operated ears with open mastoid. Acta Otolaryngol; 122: 249-254. 
28. Abramovich S, Hannan SA, Huins CT , Georgalas C , McGuinness J , Vats A , Thompson I (2008) : Prospective cohort comparison of bioactive glass implants and conchal cartilage in reconstruction of the posterior canal wall during tympanomastoidectomy . Clinical Otolaryngology.;33(6):553-559.

29. Lossdorfer S, Schwartz, Lohmann $\mathrm{CH}$, Greenspan DC, Ranly DM, Boyan BD (2004): Osteoblast response to bioactive glass in vitro correlates with inorganic phosphate content. Biomaterials. Jun; 25(13)2547-55

30. Allan I., Wilson M. \& Newman H. (2002): Particulate Bioglass reduces the viability of bacterial biofilms formed on its surface in an in vitro model. Clin. Oral Implants Res; 13: 53-58

31. Schwager K(1998): Titanium as an ossicular replacement material. Results after 336 days of implantation in the rabbit. Am J Otol(19): 569573

32. TATEKI KUBO, KOICHI TOMITA, AKIYOSHI TAKADA, KENJI YANO \& KO HOSOKAWA (2009): Reconstruction of adult auricular defect with thin titanium mesh and prelaminated free radial forearm flap. Scand J Plast Reconstr Surg Hand Surg( 43): 54-57

33. Sarin J , Grénman R , Aitasalo K , Pulkkinen J (2012): Bioactive Glass S53P4 in Mastoid Obliteration Surgery for Chronic Otitis Media and Cerebrospinal Fluid Leakage. Annals of Otology, Rhinology \& Laryngology 121(9):563569.
34. Black B (1995): Mastoidectomy elimination. Laryngoscope (Supple76); (105): 130

35. Rosenblunt B, Ahlvin RC, and Carr CD (1966): Silicone implants in the mastoid portion of the temporal bone. Ann Otol Rhino Laryngol (75): 889-892.

36. Shea et al (1984): Reconstruction of the posterior canal wall with Proplast. Otolaryngol Head Neck Surg. 92(3):329-33.

37. Renard JL, Felten D and Bequet D (1994): Post otoneuro surgery aluminium encephalopathy. Lancet, ii, 63-64.

38. Reck R, Storkel S and Meyer A (1988): Bioactive glass ceramics in middle ear surgery. Annals of the New York Academy of Sciences (523):100-106.

39. Stoor P, Pulkkinen J, Grenman R (2010) : Bioactive Glass S53P4 in the Filling of Cavities in the Mastoid Cell Area in Surgery for Chronic Otitis Media. Annals of Otology. Rhinology and laryngology 119(6):377-382

40. H SUDHOFF, D BRORS, A AL-LAWATI, E GIMENEZ, $\mathrm{S}$ DAZERT, H HILDMANN (2006): Posterior canal wall reconstruction with a composite cartilage titanium mesh graft in canal wall down tympanoplasty and revision surgery for radical cavities. The Journal of Laryngology \& Otology (120 ): 832-836.

41. Jung TTK, Park SK(2004): Reconstruction of mastoidectomy defect with titanium mesh. Acta Otolaryngol (124): $440-442$ 